\title{
Sanjiv Sam Gambhir obituary for EJNMMI
}

\section{Andrei lagaru $^{1} \cdot$ I. Ross McDougall ${ }^{1}$}

Published online: 6 August 2020

(C) Springer-Verlag GmbH Germany, part of Springer Nature 2020

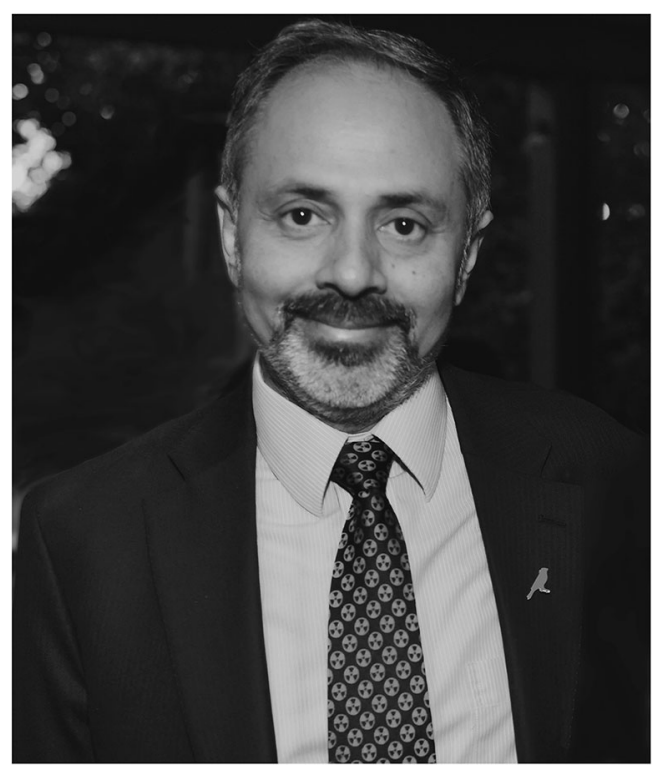

On Friday 17th of July, Professor Sanjiv "Sam" Gambhir was heralded in a stirring and moving ceremony attended online by several hundreds of his colleagues and friends. Sam was also able to watch. The President of the Stanford University and the Dean of the School of Medicine praised Sam's huge contributions in medical sciences to the University, the School of Medicine, other University Departments, to industry and most importantly to patients. Sam's wife Aruna gave a heartfelt review of their lives and careers starting in Los Angeles before settling in Northern California. Sam was awarded the Dean's Medal, the highest award of the medical school, and

This article is part of the Topical Collection on Editorial.

Picture used with permission from Dr. Sandip Biswal's collection.

Andrei Iagaru

aiagaru@stanford.edu

1 Division of Nuclear Medicine and Molecular Imaging, Department of Radiology, Stanford University, 300 Pasteur Drive, Stanford, CA 94305-5281, USA establishment of The Sanjiv "Sam" Gambhir Professorship in Translational Medicine was announced. Many of those watching were aware that Sam, our colleague and dear friend, had advanced cancer but we were shocked and saddened to learn he passed away on July 18 . He is survived by his wife Aruna, his sister, and his parents.

Sam moved from India to the USA with his family at a young age. He was an exceptionally brilliant student and matriculated at the Arizona State University at the age of 15, graduating BS summa cum laude and inducted into Phi Beta Kappa. Professor Stuart Lindsay who was one of Sam's physics teachers at ASU described his recollections of him "I first knew Sam as an undergraduate in the first class I taught at ASU, back in 1979 when Sam was a senior at the tender age of 16. He politely corrected my mistakes and I used his homework sets as my grading template."

Sam was accepted to the MD-PhD Medical Scientist Training Program at the University of California Los Angeles (UCLA), graduating $\mathrm{PhD}$ in biomathematics in 1990 and 3 years later received the gold medal as the outstanding medical student when graduating MD.

The combined education and training in physics, biomathematics, and medicine made his choice of Nuclear Medicine very fitting. He completed a residency in Nuclear Medicine at UCLA and entered the academic ranks there as an Assistant Professor of Molecular and Medical Pharmacology in 1994. He embarked on his career as an investigator, clinician, and educator each of which is described below. Sam was promoted to tenured Professor in 2003 and in the same year was selected to be Chief of the Division of Nuclear Medicine and Director of the Molecular Imaging Program at Stanford (MIPS) with the title of Professor of Radiology. Six years later, he received the endowed Virginia and D.K. Ludwig Professor for Clinical Investigation in Cancer Research.

While at UCLA, Sam published a series of clinical articles that demonstrated the cost-effectiveness of FDG PET in a variety of cancers. He consolidated these data and educated and worked with others to convince decision-makers at the Center for Medicaid and Medicare Services of the important 
independent diagnostic role of FDG PET, leading to reimbursement for PET.

Sam's arrival at the Stanford University meant a new era for both clinical and research activities in Nuclear Medicine and Molecular Imaging. While at Stanford, he mentored more than 150 graduate students and was a role model to all. His work ethic was Herculean, organized, focused, and attentive to detail. His communication with trainees was supportive and nurturing as he individualized research pathways that would help with their future careers. Dr. Gambhir inspired generations of young physicians and laboratory scientists to be better clinical and basic researchers.

His research focused on imaging to monitor fundamental cellular/molecular events in living subjects with an emphasis on cancer. Technologies employed in his laboratories included micro-positron emission tomography (microPET), bioluminescence imaging, fluorescence optical imaging, Raman optical imaging, ultrasound, and photoacoustics. Sam's research transitioned from early cancer detection to precision health, which he pioneered and was passionate about. One of his famous quotes was "We shouldn't be celebrating how full our hospitals are. We should celebrate when our hospitals are empty!". With that goal in mind, he was the instigator and director of the Canary Center at Stanford for Early Detection and the Precision Health and Integrated Diagnostic (PHIND) Center at Stanford.

In the course of basic science and clinical research, he, along with his colleagues, published almost 700 peer-reviewed papers in diverse prestigious journals. As an example over the last 24 months, usually with Sam as the senior author, articles appeared in Annals Surgical Oncology Biomaterials, Cancer Research, Circulation, Clinical Cancer Research, European Journal Nuclear Medicine, Investigative Radiology, Journal American College of Radiology, Journal Nuclear Medicine, Lancer Oncology, Molecular Imaging and Biology, Nature, Nature Biomedical Engineering, Nature Communications, Nature Nanotechnology, Nature Oncology, Nuclear Medicine Communications, and Proceedings National Academy of Sciences. Illustrations from several articles were highlighted on journal covers.

Sam along with Peter Ell edited the comprehensive textbook Nuclear Medicine in Clinical Diagnosis and Treatment; he was an author of Molecular Imaging Principles and Practice and the sole author of Molecular Imaging: A Primer.

Professor Gambhir won many honors and awards locally, regionally, nationally, and internationally. He was elected to the National Academy of Medicine in 2008, the American Association for the Advancement of Science in 2014, and the National Academy of Inventors in 2016.

Dr. Gambhir was an outstanding physician in the Nuclear Medicine and Molecular Imaging Clinic. His interpretation of scans was greatly appreciated by clinicians from all departments, and the consultations were bolstered by an encyclopedic knowledge of the field. In later years, because of increasing time constraints from his many laboratory pursuits and administrative duties, he had to relinquish the clinical duties that he loved.

Sam was an inspiring educator. This is epitomized by being awarded the Basic Science Teaching Award by the Radiology residents at Stanford in 2018, a very rare recognition for the head of a large clinical department. He always managed to make students strive to learn, often with a hint of irresistible humor. Over 2 decades, he lectured to large audiences at venues throughout the world, and his ability to take very complex subjects and make them interesting and understandable was widely acknowledged and appreciated.

Sam's wisdom and diligence were rewarded by him being invited to join and indeed chair committees responsible for Decanal and leadership appointments.

The majority of scientists and physicians across the globe "knew" Professor Gambhir through his scientific publications and presentations. However, those who really knew the person did so through personal contact. If we had to define Sam in one word, it would be "class." He was always a gentleman, no matter how busy he was, and he always had time to speak with anyone. He was modest, thoughtful, sensitive, gracious, and generous. Each year, Sam and Aruna held a welcoming party for incoming residents and fellows in their beautiful home in Portola Valley where the new trainees could meet faculty under a happy, non-threatening environment that set the scene for their upcoming years. He also held a similar annual party for Emerita Professors that was greatly appreciated. Old colleagues came together, and in the relaxed atmosphere, Sam was able to seek advice on current issues that were very similar to historic ones the old guard had experienced. The annual departmental dinner party was anticipated with excitement. The number attending grew each year as Sam built up the department, and he presented many awards to employees from all levels within the system. His leadership was a great stimulus for morale and team spirit.

A renaissance man, Sam was a walking encyclopedia, with knowledge and interests extending beyond medicine into the world of arts, literature, sports, history, and politics.

Sanjiv Sam Gambhir will be sorely missed, and we mourn with Aruna. However, he will be remembered affectionately by everyone who came in contact with him, through the huge body of his published research, the legion of medical and laboratory scientists he trained and nurtured, and the Sanjiv "Sam" Gambhir Professorship of Translational Medicine at the Stanford University.

For all his work, Sam received many honors and awards. This list includes some from the last decade: the Taplin Award, Holst Medal, Academy of Molecular Imaging (AMI) Distinguished Basic Scientist of the Year Award, Society for Molecular Imaging (SMI) Achievement Award, Distinguished Clinical Scientist Award from Doris Duke Charitable 
Foundation, Hounsfield Medal (Imperial College London), fellowship of the American Institute for Medical and Biological Engineering (AIMBE), Paul C. Aebersold Award, Organizer and Co-Chair for the Nobel Symposium in Imaging (2008), Inducted as a member of the American Society of Clinical Investigators (ASCI), Tesla Medal, Elected to the Institute of Medicine (IOM) of the US National Academies, Parmley Prize, Radiological Society of North American (RNSA) Outstanding Researcher Award, The Gopal Subramanian Lifetime Achievement Award, the George Charles de Hevesy Nuclear Pioneer Award, Aunt Minnie Award, Distinguished Scientist Award for Distinguished Contributions to Nuclear Medicine, Society of Asian American Scientists in Cancer Research Award, the American Association of Indian Scientists in Cancer Research Lifetime Achievement Award, Benedict
Cassen Prize for Research in Molecular Imaging, Institute of Electrical and Electronics Engineers (IEEE) Marie Sklodowska-Curie Award - IEEE Advancing Technology for Humanity, and the European Society of Molecular Imaging 2020 Annual Award.

\section{Compliance with ethical standards}

Conflict of interest The authors declare that they have no conflict of interest.

Ethical approval Not applicable.

Publisher's note Springer Nature remains neutral with regard to jurisdictional claims in published maps and institutional affiliations. 